\title{
Effects of minimally invasive plate-screw internal fixation in the treatment of posterior pelvic ring fracture
}

\author{
SHIGUANG LI ${ }^{1,2}$, XIANXIA MENG ${ }^{3}$, WENLONG LI $^{2}$, ZHAOYUN SUN $^{2}$, \\ XING WANG ${ }^{2}$, HONGDE QI ${ }^{2}$, SHUJU WEI $^{2}$ and DONGSHENG ZHOU ${ }^{1}$ \\ ${ }^{1}$ Department of Orthopedics, Shandong Provincial Hospital Affiliated to Shandong University, \\ Jinan, Shandong 250021; ${ }^{2}$ Department of Orthopedic Surgery, Laiwu City People's Hospital; \\ ${ }^{3}$ Laiwu Blood Center, Laiwu, Shandong 271100, P.R. China
}

Received March 13, 2018; Accepted August 10, 2018

DOI: $10.3892 / \mathrm{etm} .2018 .6670$

\begin{abstract}
Effects of minimally invasive plate-screw internal fixation and sacroiliac joint screw fixation in the treatment of posterior pelvic ring fracture were compared. Continuous selection of 20 cases of unstable pelvic posterior ring fractures, according to indications of operation, were divided into a group of 13 cases of plate-screw internal fixation and a group of 7 cases of sacroiliac joint screw fixation, and the operation effect and complications were compared. The comparisons of operation time, amount of radiation exposure, intraoperative blood loss, length of incision, partial load and full load time, and complications between two groups were carried out, and there were no statistically significant differences $(\mathrm{P}>0.05)$. The evaluation of clinical effects (based on the Majeed pelvic functional scoring criteria) and the evaluation of anatomic effects (based on Matta and Tornetta scoring criteria) between the two groups were compared, there was no statistically significant difference $(\mathrm{P}>0.05)$. Minimally invasive platescrew internal fixation and sacroiliac joint screw fixation in the treatment of the posterior pelvic instability fracture both have indications and their therapeutic effects are equally matched.
\end{abstract}

\section{Introduction}

Pelvic fractures are mostly caused by high energy injuries, such as traffic accidents, industrial accidents, crushing injuries and falling injuries, which account for $10-25 \%$ of all fractures in the body. Among them, unstable fractures account for $7-22 \%$, and the death rate of fracture is approximately $3-28 \%$, which seriously threatens both the quality and life of patients (1). Conventional conservative treatment tends

Correspondence to: Dr Dongsheng Zhou, Department of Orthopedics, Shandong Provincial Hospital Affiliated to Shandong University, 324 Jingwuweiqi Road, Jinan, Shandong 250021, P.R. China

E-mail: zr627g@163.com

Key words: minimally invasive plate-screw fixation, sacroiliac joint fixation, posterior pelvic ring instability fracture to result in pelvic deformity, limb shortening, limb wasting and recurrent fracture rate, and the disability rate is as high as $50-66 \%$ (2). Especially for unstable fractures, the active surgical reduction is recommended (3). The posterior pelvic ring consists of sacrospinous ligament, sacro-tuberous ligament, sacroiliac joint and surrounding ligament, structured in geometrically stable system, which is relatively stable and its stable effect is $60 \%$ (4). In the case of Tile B and C fracture, the internal fixation of percutaneous sacrum, sacroiliac joint screw fixation and minimally invasive plate-screw fixation can be adopted. They are all applied in clinic according to different surgical indications $(5,6)$. Previous studies have been conducted to compare the effects in the treatment of fracture of the ring instability with different surgical methods, but there is no uniform conclusion, which indicates that there are advantages and disadvantages of different operation methods $(7,8)$. This study summarized the effects of minimally invasive plate-screw internal fixation and sacroiliac joint screw fixation of posterior pelvic ring fracture.

\section{Patients and methods}

Patient information. A total of 20 patients with unstable fractures in the pelvic area were diagnosed in Laiwu City People's Hospital (Laiwu, China) from January 2014 to June 2015, excluding fractures of other parts, such as fractures of the chest and multiple fractures. Other exclusion criteria were: Hemorrhagic shock, severe infection, lower limb paralysis combined with severe anterior ring fracture, the first stage of operation cannot be completed, and the surgery needs to be performed, surgical failure, and incomplete follow-up data. The study was approved by the Ethics Committee of Laiwu City People's Hospital and was completed by the same operation and nursing team. Signed written informed consent was obtained from the patients or guardians.

According to the surgical indications, there were 13 cases (steel plate group) and 7 cases of sacroiliac screw fixation group (sacroiliac screw group). Among the steel plate group, 8 were males and 5 were females, aged 26-48 years, (average $35.7 \pm 12.3$ years), the onset time was $1-12 \mathrm{~h}$ (average $5.3 \pm 2.5 \mathrm{~h}$ ), tile somatotype B type 7 cases, and C type 6 cases. Denis somatotype standard I, 4 cases; standard II, 6 cases; 

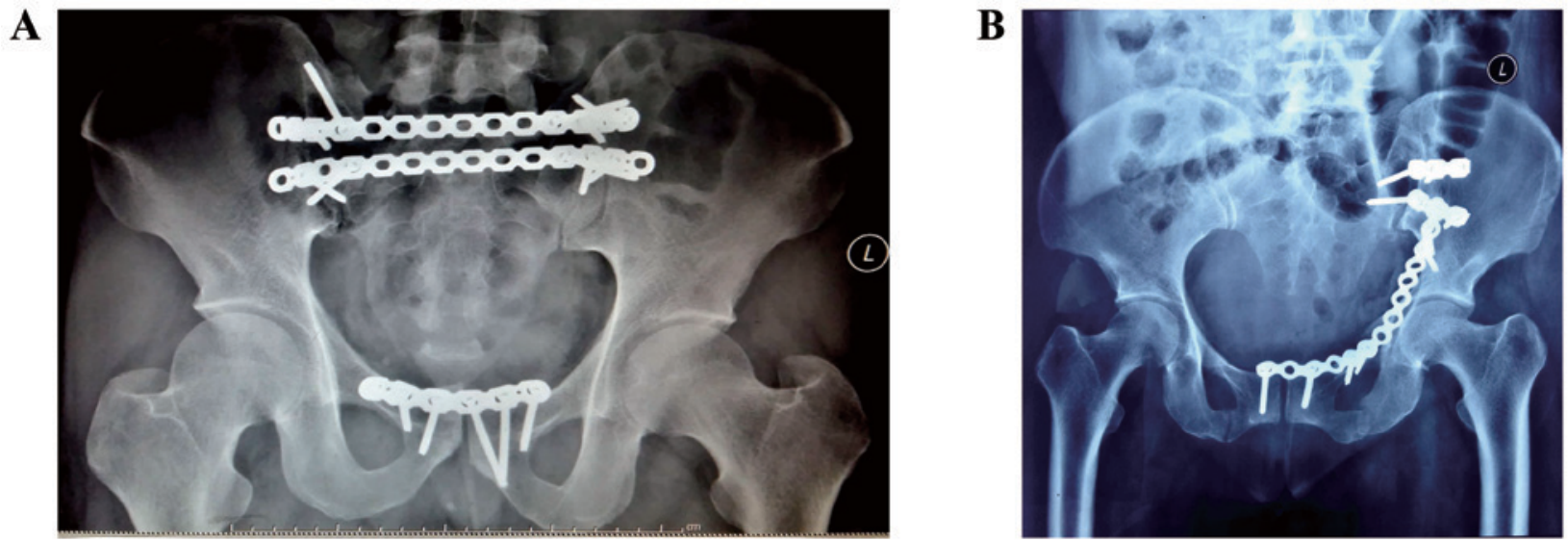

Figure 1. Fixed diagrammatic sketch of posterior pelvic ring fracture. (A) Left side was fixed with the posterior tensile steel plate fixation: Left sacroiliac fracture dislocation and left pubic branch, ischial branch fracture Tile type C. (B) The right side was fixed with the percutaneous sacroiliac joint screw fixation: Right sacroiliac joint fracture dislocation and the pubic branch, the ischial branchfracture Tile type $\mathrm{C}$ type.

standard III, 3 cases. Six cases of injury caused by accident, 4 cases caused by falling from height, 3 cases caused by crushing, 5 cases of combined intestinal injury, 2 cases of urethra and bladder injury, 3 cases of soft tissue open injury, and 3 cases of sacral plexus nerve injury. Among sacroiliac screw group, 5 were males and 2 were females, aged 23-46 years (average 33.6 \pm 11.4 years), the onset time was $1.5-12.5 \mathrm{~h}$ (average $5.5 \pm 2.6 \mathrm{~h}$ ), tile somatotype B type 6 cases, and C type 1 case. Denis somatotype standard I, 3 cases; standard II, 3 cases; standard III, 1 case. Four cases of injury caused by accident, 2 caused by falling from height, 1 caused by crushing, 2 of combined intestinal injury, 2 of urethra and bladder injury, 2 of soft tissue open injury, and 1 case of sacral plexus nerve injury. Baseline data of the two groups were not statistically significant $(\mathrm{P}>0.05)$.

Operation method. Two groups of patients were treated with systemic chemotherapy. This includes stabilizing vital signs, treating various blood loss, hypoxia, rehydration, electrolyte and acid-base balance, infection, and treating open wounds, searching for potential wounds, preventing complications, completing various examinations and assessing the risks of surgery. Posterior tension band steel surgical indications: After preoperative traction reduction of sacroiliac joint fracture dislocation Denis classification I, II, III area sacrum with vertical fracture, sacroiliac joint dislocation after iliac spine fracture or iliac wing fractures. Contraindications: Old fracture cannot be reset, severe osteoporosis, large soft tissue injury in the posterior ring area, obvious weight loss, flat surface of steel plate top pressure. Percutaneous sacrosacroiliac screw fixation syndrome: Five days after injury, preoperative traction caused pelvic reposition, severe soft tissue injury, intestinal injury or both. Contraindications: Closed reduction failure, $\mathrm{C}$-arm cannot see the posterior lateral and lateral structure of the sacrum, the sacrum deformity and osteoporosis.

Posterior tension belt plate fixation. Selecting general anesthesia, prone position, and the longitudinal incision of $3-4 \mathrm{~cm}$ on the lateral iliac spine of the posterior superior iliac spine, dissecting the attachment of the gluteal superior iliac spine, revealing the posterior side of the iliac flank, exposing the fracture line, removing sacroiliac articular cartilage, and correcting the fracture and dislocation of sacroiliac joint by pulling, prying and squeezing. Preparing the 14-16 hole with one or two pieces of steel plate, inserting steel plate respectively along the sacrum subcutaneous tunnel to the contralateral posterior spine, crossing the sacrum, bending steel plate on both sides of a bow to adapt to the spines on the slope after skeletons, making side plate appropriate for long fracture dislocation; after C-arm machine proved fracture or dislocation position can be accepted, turning the screws in turn on both sides; plate length ensured that both sides can be fixed with more than three screws. After iliac spine on the vertex angle of the screw down along the ilium between inner and outer plate, intraoperative probes for sounding are available, and borehole walls are bone, which will have long cancellous bone screw into the iliac crest, and postoperative iliac cancellous bone graft (Fig. 1).

Percutaneous sacroiliac joint screw fixation. General anesthesia machine, supine, $\mathrm{C}$-arm to rotate photographs of entrance and exit, lumbar di ministry soft pillow up hip pad through X-ray, below the surface of the skin before the entry point is located in the femoral screw axis and iliac spines on the perpendicular intersection point $<2 \mathrm{~cm}$, skin incision, gram in ilium posterolateral needle, and show needle point to push S1 perpendicular to the sacroiliac joint. C-arm machine line side, confirmed that the guide for S1 vertebral was central, accurate location, needle to S1 vertebral body direction, until export to the outside of the needle tip to S1 nerve hole on the surface. Reposition the lateral perspective to confirm that the guide tip is in the safe zone of S1. The whole process should be completed in three directions under the perspective; if the needle position is good, immediately turned the screw, not using excessive reset or pressure, in order to avoid injury of nerve root, and trying not to make the screw over the midline (Fig. 1).

Postoperative treatment. Postoperative treatment involved: Hip knee joint activities, muscle strength training, turning over and lying on the side, being in semi-reclining position after 1 week, sitting in a wheelchair at 2-4 weeks, walking 
Table I. Comparison of perioperative indicators.

\begin{tabular}{lcccccc}
\hline Groups & $\begin{array}{c}\text { The operation } \\
\text { time (min) }\end{array}$ & $\begin{array}{c}\text { Radiation } \\
\text { exposure }(\mathrm{Gy})\end{array}$ & $\begin{array}{c}\text { Intraoperative } \\
\text { blood loss }(\mathrm{ml})\end{array}$ & $\begin{array}{c}\text { The length of } \\
\text { the incision }(\mathrm{cm})\end{array}$ & $\begin{array}{c}\text { Partial load } \\
\text { time (day) }\end{array}$ & $\begin{array}{c}\text { Full load } \\
\text { time (day) }\end{array}$ \\
\hline Steel & $65.8 \pm 9.6$ & $56.7 \pm 6.7$ & $326.4 \pm 34.2$ & $7.8 \pm 1.2$ & $6.5 \pm 1.3$ & $24.7 \pm 3.4$ \\
Sacroiliac screw & $61.2 \pm 10.2$ & $53.3 \pm 6.9$ & $335.7 \pm 26.8$ & $7.6 \pm 1.3$ & $6.3 \pm 1.4$ & $25.8 \pm 3.3$ \\
t-value & 0.637 & 0.768 & 0.649 & 0.329 & 0.729 & 0.492 \\
P-value & 0.428 & 0.539 & 0.755 & 0.487 & 0.632 & 0.527 \\
\hline
\end{tabular}

Table II. Comparison of clinical effect evaluation and anatomic effect evaluation [case (\%)].

\begin{tabular}{|c|c|c|c|c|c|c|c|c|c|}
\hline \multirow[b]{2}{*}{ Groups } & \multirow[b]{2}{*}{ No. of cases } & \multicolumn{4}{|c|}{ Clinical effect evaluation } & \multicolumn{4}{|c|}{ Anatomic effect evaluation } \\
\hline & & Optimum & Fair & Medium & Poor & Optimum & Fair & Medium & Poor \\
\hline Steel & 13 & $3(23.1)$ & $3(23.1)$ & $4(30.8)$ & $3(23.1)$ & $2(15.4)$ & $3(23.1)$ & $3(23.1)$ & $5(38.5)$ \\
\hline Sacroiliac screw & 7 & $1(14.3)$ & $2(28.6)$ & $3(42.9)$ & $1(14.3)$ & $1(14.3)$ & $2(28.6)$ & $1(14.3)$ & $3(42.9)$ \\
\hline$\chi^{2}$ & & 0.400 & & & & 0.265 & & & \\
\hline P-value & & 0.940 & & & & 0.968 & & & \\
\hline
\end{tabular}

with crutches with part load after 4 weeks, and gradually to full load, trying to walk without crutches after 6 months, trying to half crouch after 8 months.

Observation indexes. During the follow-up of approximately 1 year, the indexes of perioperative period, including operation time, radiation exposure, intraoperative blood loss, incision length, partial load time and total load time, and the complications occurred were compared. Clinical effect evaluation: According to patients' life self-care ability, pain degree, degree of dysfunction and fracture healing, Function rating criteria: Majeed pelvis (9), 85-100 was considered optimal, 70-84 was good, 55-69 was medium, and $\leq 54$ was poor. Anatomic effect evaluation: According to the Matta and Tornetta standard (10) pelvic posterior ring displacement of $\leq 4 \mathrm{~mm}$ is optimal, $4-10 \mathrm{~mm}$ is good, $11-20 \mathrm{~mm}$ is medium and $>20 \mathrm{~mm}$ is poor.

Statistical methods. Using SPSS 19.0 (IBM Corp., Armonk, NY, USA) statistical software for input and analysis of quantitative data to average \pm standard deviation, comparison between groups using independent sample t-test, qualitative data using the number of cases or percentage (\%), the comparison between group using Chi-square test $\left(\chi^{2}\right)$, level data by using rank and inspection. $\mathrm{P}<0.05$ was considered to indicate a statistically significant difference.

\section{Results}

Comparison of perioperative indicators. There was no statistically significant difference between the two groups of surgical time, radiation exposure, intraoperative bleeding, incision length, partial load time and total load time $(\mathrm{P}>0.05)$ (Table I).

Comparison of complications. In steel plate group, 3 cases of incision and internal plant infection, 2 cases of intraoperative blood vessel and nerve injury, 1 case of displacement of steel plate, 3 cases of fracture of internal fixation and curved nail, 1 case of bone not healing, a total of 10 cases of complications $(21.7 \%)$. In sacroiliac screw group, there were 2 cases of incision and internal plant infection, 3 cases of intraoperative blood vessel and nerve injury, 5 cases of fracture of internal fixation and curved nail, 2 cases of bone not healing, a total of 12 cases of complications (30.0\%). Comparing complication rates between the two groups, there was no statistically significant difference (Chi-square $=0.767, \mathrm{P}=0.767$ ) (Data not shown).

Comparison of clinical effect evaluation and anatomic effect evaluation. In the comparison of clinical effect evaluation and anatomic effect evaluation between the groups, there was no statistically significant difference $(\mathrm{P}>0.05)$ (Table II).

\section{Discussion}

Matta and Tornetta (10) reported for the first time, closed reduction and satisfactory dislocation of sacroiliac joint position, percutaneous implantation of sacroiliac joints under perspective screws, clinical effect was satisfactory, and the sacroiliac joint screw fixation was centric, the fixed strength was more than steel plate internal fixation, small surgical trauma, good stability and less complications. Routt et al (11) found that percutaneous sacroiliac screw implanting in S1 vertebral body, there is a narrow area of security, and the front is iliac wing slope cortex, the left L5 nerve root and iliac blood vessels, and the rear of the security area is S1 nerve root hole, and implant screw should be in pelvic inlet and outlet, and the sacrum is oblique perspective under the auxiliary. The biomechanical study confirmed that (12), S1, S2, parallel double screw had better pelvic ring stability than single S1 screw. Type C-Arm X-ray machine perspective can be safely inserted under tension screw, but X-ray machine under the perspective of sacroiliac complex three-dimensional structure 
of the image is not accurate; for patients with obesity, pneumatosis lumen X-ray image is blurred, and intraoperative needs to take an entrance and exit, and the needle point location is difficult to grasp, repeatedly in perspective. Nelson and Duwelius (13) reported the satisfactory curative effect of CT guided percutaneous sacroiliac screw fixation for posterior pelvic fracture. CT guided percutaneous nailing accurate operation, with small surgical trauma and radioactive damage, and can maintain the continuity of the fracture surrounding soft tissue, and biomechanical stability is high, which has fewer complications, and patients are active earlier. The disadvantages are that patients must be moved to the CT room, and the operation is cumbersome, which increases the risk of infection, and there is a possibility of fracture remigration. Computer assisted orthopaedic surgery (CAOS) has been increasingly applied to treating pelvic fractures due to its numerous advantages (14). CAOS intraoperatively can directly obtain image simulation of the operation, again without perspective to find the needle point. No replacement of the surgical position is needed when the pelvic and posterior rings are fixed at the same time, which can effectively reduce the operation time and patients X-ray radiation. But the development time of CAOS in orthopaedic treatment is shorter, with complex equipment, complicated operation, long learning curve, and high price. Only some medical institutions with better conditions can carry out these operations. So the CAOS is still in the stage of clinical research, with its unique advantages, which still has a broad application prospect.

Krappinger et al (15) treated 31 cases of Tile type C pelvic ring fractures with minimally invasive plate-screw fixation, which achieved satisfactory clinical efficacy. They considered the unstable pelvic fractures minimally invasive plate can effectively be fixed, reconstructing the stability of pelvic ring, reduced the incidence of iatrogenic neural tissue and vascular injury. The disadvantages are the poor success rate of the anatomical repositioning, needing bridge bilateral sacroiliac joints at the same time, and taking out the steel plate later. Reconstruction plate internal fixation was characterized by simple operation, small trauma, firm fixing, and the steel plate is easy to shape. Applied to bilateral and comminuted sacroiliac complex injuries, the fixing and reconstruction plate not only can maintain reset, but also does not produce any compression effect on the sacral foramen and sacral canal, as to avoid the injury of sacral nerve and pelvic vessels (16).

Through this study, we concluded that the operation time, amount of radiation exposure, intraoperative blood loss, length of incision, partial load and full load time, and comparison of complications between the two groups, there were no statistically significant differences. There were no significant differences between the two groups in the evaluation of clinical effect and the evaluation of anatomical effects.

In conclusion, minimally invasive plate-screw internal fixation and sacroiliac joint screw fixation in the treatment of posterior pelvic ring fracture both have indications and their therapeutic effects are about the same. We will increase the sample size, extend the follow-up time, expand the selected population for prospective study in further studies, in order to master the respective indications, improve the surgical effect, and reduce the complications.

\section{Acknowledgements}

Not applicable.

\section{Funding}

No funding was received.

\section{Availability of data and materials}

The datasets used and/or analyzed during the present study are available from the corresponding author on reasonable request.

\section{Authors' contributions}

SL wrote this manuscript. SL, DZ XM and WL collected and analyzed the data. ZS and XW performed the experiments. HQ and SW interpreted the results. DZ revised and finalized this study. All authors read and approved the final manuscript.

\section{Ethics approval and consent to participate}

The study was approved by the Ethics Committee of Laiwu City People's Hospital (Laiwu, China). Patients who participated in this research, had complete clinical data. Informed consent was obtained from the patients or guardians.

\section{Patient consent for publication}

Not applicable.

\section{Competing interests}

The authors declare that they have no competing interests.

\section{Reference}

1. Acker A, Perry ZH, Blum S, Shaked G and Korngreen A: Immediate percutaneous sacroiliac screw insertion for unstable pelvic fractures: Is it safe enough? Eur J Trauma Emerg Surg 14: 5-6, 2016.

2. Costantini TW, Coimbra R, Holcomb JB, Podbielski JM, Catalano R, Blackburn A, Scalea TM, Stein DM, Williams L, Conflitti J, et al; AAST Pelvic Fracture Study Group: Current management of hemorrhage from severe pelvic fractures: Results of an American Association for the Surgery of Trauma multi-institutional trial. J Trauma Acute Care Surg 80: 717-723, discussion 723-725, 2016.

3. Buller LT, Best MJ and Quinnan SM: A nationwide analysis of pelvic ring fractures: Incidence and trends in treatment, length of stay, and mortality. Geriatr Orthop Surg Rehabil 7: 9-17, 2016.

4. Fan Y, Lei J, Liu H, Li Z, Cai X and Chen W: Three-dimensional finite element analysis to T-shaped fracture of pelvis in sitting position. Sheng Wu Yi Xue Gong Cheng Xue Za Zhi 32: 997-1003, 2015 (In Chinese).

5. Halawi MJ: Pelvic ring injuries: Surgical management and long-term outcomes. J Clin Orthop Trauma 7: 1-6, 2016.

6. Prasarn ML, Horodyski M, Schneider PS, Pernik MN, Gary JL and Rechtine GR: Comparison of skin pressure measurements with the use of pelvic circumferential compression devices on pelvic ring injuries. Injury 47: 717-720, 2016.

7. Shrestha D, Dhoju D, Shrestha R and Sharma V: Percutaneous ilio-sacral screw fixation in supine position under fluoroscopy guidance. Kathmandu Univ Med J KUMJ 13: 56-60, 2015.

8. Liu XM, Pan CW, Wang GD, Cai XH, Chen L, Meng CF and Huang JC: Finite element analysis of the stability of combined plate internal fixation in posterior wall fractures of acetabulum. Int J Clin Exp Med 8: 13393-13397, 2015. 
9. Majeed SA: Grading the outcome of pelvic fractures. J Bone Joint Surg Br 71: 304-306, 1989.

10. Matta JM and Tornetta P III: Internal fixation of unstable pelvic ring injuries. Clin Orthop Relat Res 329: 129-140, 1996.

11. Routt ML Jr, Simonian PT, Agnew SG and Mann FA: Radiographic recognition of the sacral alar slope for optimal placement of iliosacral screws: A cadaveric and clinical study. J Orthop Trauma 10: 171-177, 1996.

12. Cai HM, Liu YW, Li HJ, Wu XJ, Tang HT, Zhang Y, Jia YD and Li WY: S2 iliosacral screw insertion technique. Zhongguo Gu Shang 28: 910-914, 2015 (In Chinese).

13. Nelson DW and Duwelius PJ: CT-guided fixation of sacral fractures and sacroiliac joint disruptions. Radiology 180: 527-532, 1991.

14. Collinge C, Coons D, Tornetta P and Aschenbrenner J: Standard multiplanar fluoroscopy versus a fluoroscopically based navigation system for the percutaneous insertion of iliosacral screws: A cadaver model. J Orthop Trauma 19: 254-258, 2005.
15. Krappinger D, Larndorfer R, Struve P, Rosenberger R, Arora R and Blauth M: Minimally invasive transiliac plate osteosynthesis for type $\mathrm{C}$ injuries of the pelvic ring: A clinical and radiological follow-up. J Orthop Trauma 21: 595-602, 2007.

16. Kobbe P, Hockertz I, Sellei RM, Reilmann H and Hockertz T: Minimally invasive stabilisation of posterior pelvic-ring instabilities with a transiliac locked compression plate. Int Orthop 36: 159-164, 2012.

This work is licensed under a Creative Commons Attribution-NonCommercial-NoDerivatives 4.0 International (CC BY-NC-ND 4.0) License. 